\title{
The syndrome of progressive posterior cortical dysfunction A multiple case study and review
}

\author{
Renata Areza-Fegyveres ${ }^{1}$, Paulo Caramelli ${ }^{2}$, Claudia Sellitto Porto ${ }^{3}$, \\ Carla Rachel Ono ${ }^{4}$, Carlos Alberto Buchpiguel ${ }^{5}$, Ricardo Nitrini ${ }^{6}$
}

\begin{abstract}
Dementia presenting with prominent higher order visual symptoms may be observed in a range of neurodegenerative conditions and is often challenging to diagnose. Objectives: To describe cases of progressive dementia presenting with prominent visual cortical symptoms. Methods: We conducted a retrospective search of cases of progressive dementia with predominant visual symptoms, seen at our dementia unit from 1996 to 2006. Results: Twelve patients ( 5 men, 7 women) were identified, with ages ranging from 49 to 67 years. At the first examination, the duration of the symptoms ranged from one to ten years and the Mini-Mental State Examination scores from 7 to 27. Eleven patients presented with predominant visuospatial symptoms (partial or complete Balint syndrome) and one with visuoperceptive impairment. Other reported manifestations were: constructional apraxia in 11 patients, partial or complete Gerstmann syndrome in ten, ideomotor apraxia in nine, hemineglect or extinction in four patients, alien hand phenomenon in three, and prosopagnosia in one patient. Memory loss was reported by ten patients, but was not the main complaint in any of these cases. Insight was relatively preserved in five patients even after a long period following the onset of symptoms. Six patients developed parkinsonism during evolution. Clinical diagnoses were possible or probable AD in seven patients, cortico-basal degeneration in four, and dementia with Lewy body in one. Conclusions: Clinicians should consider this condition especially in presenile patients with slowly progressive higher-order visual symptoms. Although described in association with different conditions, it may also occur in Alzheimer disease.
\end{abstract}

Key words: posterior cortical atrophy, syndrome of progressive posterior cortical dysfunction, Alzheimer disease, visual symptoms.

\begin{abstract}
Síndrome de disfunção cortical posterior progressiva: um estudo de múltiplos casos e revisão
Resumo - As demências que se apresentam predominantemente com sintomas visuais associativos podem ser observadas em diferentes condições neurodegenerativas, sendo seu diagnóstico muitas vezes desafiador. Objetivos: Descrever as principais características clínicas de pacientes com demência progressiva que se apresentam com sintomas visuais proeminentes. Métodos: Conduzimos estudo retrospectivo de casos com demência progressiva com sintomas visuais predominantes vistos no nosso ambulatório de demência, no período de 1996 até 2006. Resultados: Doze pacientes (5 homens e 7 mulheres) foram identificados, com idades variando entre 49 e 67 anos. Na primeira consulta, duração de sintomas variou de um a dez anos e a pontuação do Mini-Exame do Estado Mental variou de 7 a 27 pontos. Onze pacientes apresentaram sintomas visuoespaciais predominantes (Síndrome de Bálint parcial ou completa) e um apresentou alteração visuoperceptiva. Outras manifestações relatadas foram: apraxia construtiva em 11 pacientes, síndrome de Gerstmann parcial ou completa em 10 pacientes, apraxia ideomotora em nove, heminegligência ou extinção em 4 pacientes, fenômeno da mão alienígena em 3 e prosopagnosia em um paciente. Queixa de perda de memória foi referida em 10 pacientes, mas em nenhum deles como queixa principal. Juízo crítico era preservado em cinco pacientes até estágios moderados da doença. Seis pacientes desenvolveram parkinsonismo ao longo da evolução. O diagnóstico clínico foi DA possível
\end{abstract}

\footnotetext{
${ }^{1}$ Neurologist, member of the Behavioral and Cognitive Neurology Unit, Department of Neurology, University of São Paulo School of Medicine, São Paulo, SP, Brazil. ${ }^{2}$ Associate Professor of Neurology, Department of Internal Medicine, Faculty of Medicine, Federal University of Minas Gerais, Belo Horizonte, MG, Brazil. ${ }^{3}$ Neuropsychologist, member of the Behavioral and Cognitive Neurology Unit of the University of São Paulo School of Medicine. ${ }^{4}$ Nuclear Medicine Physician, Division of Nuclear Medicine, Department of Radiology, University of São Paulo School of Medicine. ${ }^{5}$ Associate Professor, Department of Radiology (Nuclear Medicine), University of São Paulo School of Medicine. ${ }^{6}$ Associate Professor, Department of Neurology, University of São Paulo School of Medicine.
}

Renata Areza-Fegyveres - Rua Oscar Freire, 1702 / 44 - 05409-011 São Paulo SP - Brasil. E-mail: renataareza@yahoo.com.br 
ou provável em sete pacientes, degeneração corticobasal em quatro e demência com corpos de Lewy em um paciente. Conclusões: Os clínicos devem ter em mente essa condição especialmente em pacientes pré-senis com queixas visuais complexas e lentamente progressivas. Apesar de descritas em diferentes condições, pode ocorrer na doença de Alzheimer.

Palavras-chave: atrofia cortical posterior, síndrome de disfunção cortical posterior progressiva, doença de Alzheimer, sintomas visuais.

The past three decades have seen a body of reports on patients suffering neurodegenerative disease with disruption of visual processing together with relative preservation of memory and insight. In 1988, Benson et al. described five patients with predominant higher order visual signs and symptoms which they denominated posterior cortical atrophy (PCA). ${ }^{1}$ Their patients developed alexia, agraphia, visual agnosia, partial or complete Bálint and Gerstmann syndromes, as well as transcortical sensory aphasia. Memory, insight and judgment were relatively preserved up until moderate stages of the disease. No pathologic specimens were available for their study. The authors speculated whether the underlying pathologic condition included a variant of Alzheimer disease (AD), a lobar atrophy analogous to Pick's disease or a new unrecognized entity. ${ }^{1}$

PCA comprises disorders of either visuospatial processing or visual recognition, resulting from the dysfunction of parieto-occipital and temporo-occipital pathways, respectively. ${ }^{2}$ Visuospatial processing disorders are more frequent, although both may occur in the same patient.

After Benson et al. ${ }^{1}$ characterized and named PCA as a distinct phenotype, there have been two other attempts to improve clinical diagnostic criteria based on the growing literature on this issue. ${ }^{3,4}$ Tang-Wai et al. ${ }^{3}$ proposed a subset of diagnostic criteria for PCA based on their neuropathological and clinical findings. In addition, they proposed to rename the syndrome based on its concept and not on imaging findings: the syndrome of posterior progressive cortical dysfunction (SPPCD).

While the clinical presentation is relatively homogeneous, multiple etiologies can account for this syndrome. Recent studies involving autopsied series of cases have shown that $\mathrm{AD}$ with atypical distribution of pathological lesions, corticobasal degeneration (CBD), Creutzfeldt-Jakob disease and dementia with Lewy bodies (DLB) might underlie this syndrome. The most common etiology by far is $\mathrm{AD},{ }^{3,5-10}$

The aim of the present study was to describe cases of progressive dementia that presented with prominent visual cortical symptoms in an outpatient clinic specialized in dementia.

\section{Methods}

A retrospective search of the case files from 1996 to 2006 of the Behavioral and Cognitive Neurology Unit, which is linked to a public university hospital, was undertaken. Approximately 700 files were examined. Other possible cases seen by the members of the Unit at other sites, mainly their private offices, were also included in the investigation.

For the diagnosis of progressive posterior cortical dysfunction, the criteria proposed by Tang-Wai et al. were used. ${ }^{3}$ Briefly, patients had to present visual complaints in the absence of significant primary ocular disease, explaining symptoms with insidious onset and gradual progression, relative preservation of anterograde memory and insight early in the disorder, disabling visual impairment throughout the disorder, absence of stroke or tumor and any of the following findings: simultanagnosia with or without optic ataxia or ocular apraxia, constructional dyspraxia, visual field defect, environmental disorientation or any of elements of Gerstmann syndrome.

The neuroimaging data were collected from the patients' charts retrospectively, without further review.

Diagnoses were established in a consensus meeting following established criteria for $\mathrm{AD},{ }^{11} \mathrm{CBD}^{12}$ and $\mathrm{DLB} .{ }^{13}$

\section{Results}

Twelve patients, 5 men and 7 women, were identified. The main demographic features as well as the duration of the symptoms up prior to the first consultation and initial Mini-Mental State Examination (MMSE) ${ }^{14,15}$ scores are shown in Table 1. Eleven patients came from the Cognitive and Behavioral out-patient clinic of the university hospital and one from the private clinic of one of the authors.

Complaints of visual impairment led five patients to seek an ophthalmologic consultation, before a neurological examination. Caregivers' main visual complaints included: "she looks but doesn't see", "she doesn't see objects in front of her and she keeps searching for them with her hands", "he bumps into furniture and behaves like a blind person", "he forgot one side of the body".

All patients presented presenile onset (Table 1). The frequency of symptoms in our case series ranged according to the stage of the disease (Figure 1). Insight for the deficits was preserved in five patients. Complaints of memory were present in all of cases, but were not considered the main symptom. Nine patients presented partial Bálint syndrome at onset while two presented the full syndrome. At onset, 
Table 1. Demographic features of twelve patients with progressive dementia and prominent visual symptoms.

\begin{tabular}{lccc}
\hline & Mean $\left(\mathrm{SD}^{\star}\right)$ & Median & Minimum/maximal values \\
\hline Age at first consultation & $59.42(5.71)$ & 60 & $49-67$ \\
Age at onset & $55.27(6.42)$ & 53 & $48-65$ \\
Schooling years & $8.36(5.55)$ & 4 & $3-16$ \\
Interval between onset of symptoms & $52.73(40.91)$ & 36 & $12-120$ \\
and first consultation (months) & $14(7.10)$ & 12 & $7-27$ \\
Mini-Mental State Exam & & & \\
\hline
\end{tabular}

${ }^{\star} \mathrm{SD}$, standard deviation.

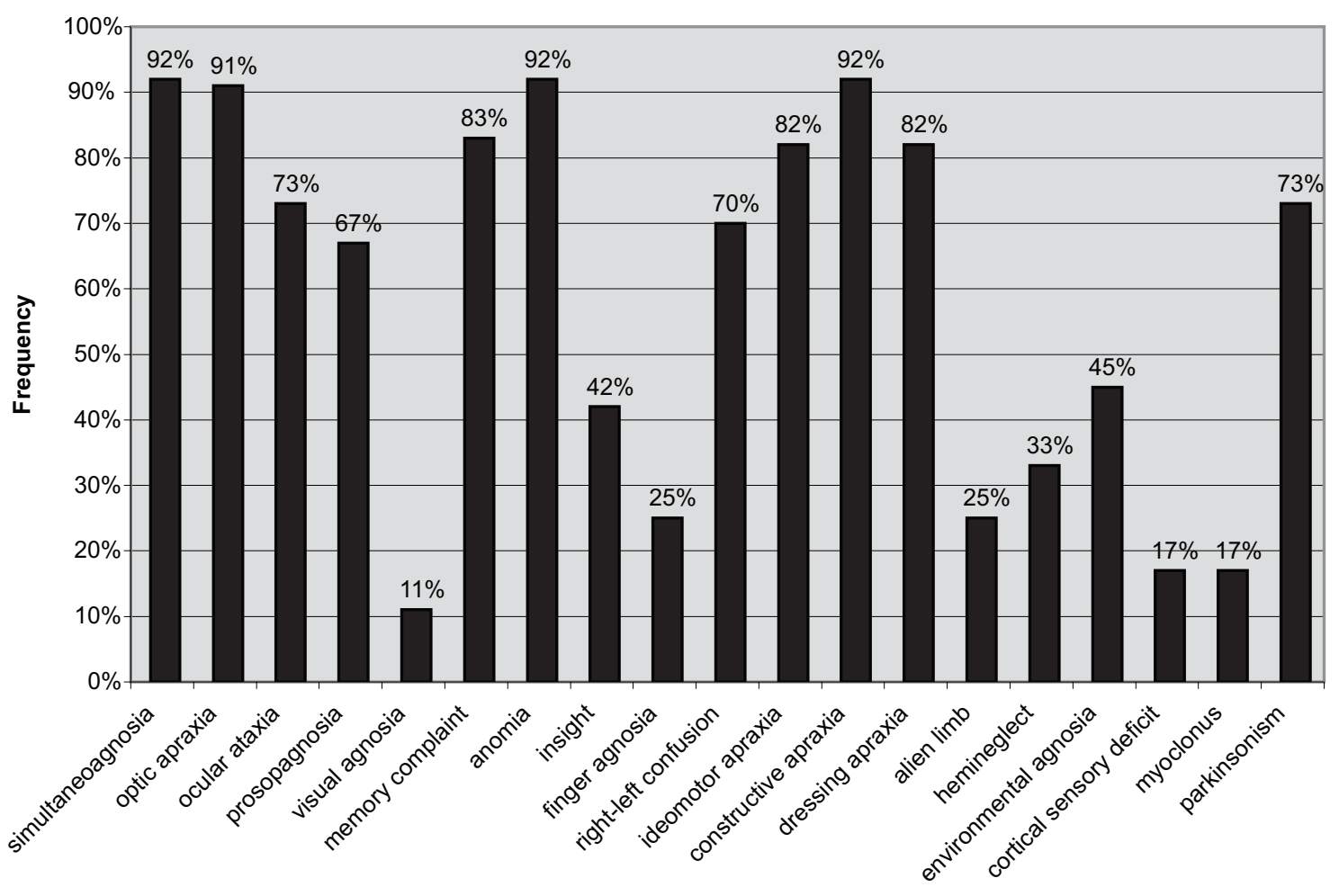

Signs and symptoms

Figure 1. Frequency of signs and symptoms of twelve patients with SPPCD. ${ }^{\star} S P P C D$, syndrome of progressive posterior cortical dysfunction.

three patients presented with partial Gerstmann syndrome. Hemineglect was present in four patients and appeared at late stages of disease. Ideomotor apraxia was present in nine subjects ranging from mild to severe. Eleven patients had constructional apraxia and nine patients had difficulty dressing.

Visual associative agnosia was reported in one patient. The most common behavioral and neuropsychiatric symptom was depressed mood which was reported by seven patients at the first outpatient visit. Parkinsonism was present in six patients: in five it was asymmetric and presented at early stages of the disease.

Educational level was very heterogeneous and ranged from 3 to 20 years. MMSE scores ranged from 7 to 27, most common errors being related to attention/calculation (12 patients), recall (12 patients), written command (9 patients) and drawing (12 patients). According to MMSE Brazilian normative data, 11 patients presented scores below those expected for their age and schooling. ${ }^{15}$ Only six out of 12 patients were able to complete the test of delayed recall of objects presented as line drawings from the Brief Cognitive Screening Battery, ${ }^{16-18}$ where severe visual perception impairment presented by the remaining six subjects hampered completion. Five patients showed low scores for delayed recall after the interference tasks. Category fluency (animals per minute) ${ }^{19,20}$ and Digit Span (forward and backwards $)^{21-23}$ were found to be impaired in the nine patients. 
Table 2. Structural and functional imaging findings of twelve patients with SPPCD*.

\begin{tabular}{|c|c|c|c|}
\hline Case & Clinical diagnosis & Structural imaging $\left(\mathrm{CCT}^{\dagger}\right.$ or $\left.{ }^{\ddagger} \mathrm{MRI}\right)$ & Functional imaging (conventional SPECT ${ }^{\S}$ ) \\
\hline 1 & "AD-SPPCD & ${ }^{*} \mathrm{MRI}$ : diffuse severe atrophy & $\begin{array}{l}\text { Temporo-parietal posterior hypoperfusion with } \\
\text { extension to frontal regions bilaterally }\end{array}$ \\
\hline 2 & "AD-SPPCD & $\begin{array}{l}{ }^{*} \text { MRI: diffuse moderate atrophy. Temporal lobes } \\
\text { relatively preserved in contrast to hippocampal } \\
\text { volume. }\end{array}$ & Not done \\
\hline 3 & "AD-SPPCD & ${ }^{*}$ MRI: diffuse severe atrophy & Left occipital hypoperfusion \\
\hline 4 & "AD-SPPCD & ${ }^{*}$ MRI: diffuse moderate atrophy & Hypoperfusion in both temporal lobes \\
\hline 5 & "AD-SPPCD & $\begin{array}{l}{ }^{*} \text { MRI: mild leukoaraiosis and cortical atrophy } \\
\text { especially in posterior lobes }\end{array}$ & $\begin{array}{l}\text { Marked hypoperfusion in parietal lobes, especially } \\
\text { to right with right fronto-temporal extension }\end{array}$ \\
\hline 6 & ${ }^{\circ} \mathrm{CBD}-\mathrm{SPPCD}$ & $\begin{array}{l}{ }^{\ddagger} \mathrm{MRI} \text { : diffuse atrophy, more marked in fronto- } \\
\text { temporal regions }\end{array}$ & $\begin{array}{l}\text { Diffuse cortical irregularity; hypoperfusion in } \\
\text { high frontal regions }\end{array}$ \\
\hline 7 & ${ }^{\circ} \mathrm{CBD}-\mathrm{SPPCD}$ & ${ }^{*}$ MRI: left parietal atrophy & Left temporo-parietal hypoperfusion \\
\hline 8 & ${ }^{\circ} \mathrm{CBD}-\mathrm{SPPCD}$ & $\begin{array}{l}{ }^{\ddagger} \mathrm{MRI} \text { : diffuse atrophy; mild hippocampal } \\
\text { atrophy, more marked than the rest of the brain }\end{array}$ & Bilateral temporo-parietal hypoperfusion \\
\hline 9 & "AD-SPPCD & ${ }^{*}$ MRI: diffuse cortical atrophy & Not done \\
\hline 10 & ${ }^{9} \mathrm{CBD}-\mathrm{SPPCD}$ & $\begin{array}{l}{ }^{*} \text { MRI: Diffuse atrophy, especially posterior. Very } \\
\text { mild leukoaraiosis. }\end{array}$ & $\begin{array}{l}\text { Bilateral temporo-parietal posterior } \\
\text { hypoperfusion with extension to frontal regions }\end{array}$ \\
\hline 11 & "AD-SPPCD & ${ }^{\dagger} \mathrm{CCT}:$ mild right parietal atrophy & $\begin{array}{l}\text { Bilateral temporo-parietal hypoperfusion, more } \\
\text { evident on right, with mild extension to right } \\
\text { frontal region }\end{array}$ \\
\hline 12 & ${ }^{* *}$ DLB-SPPCD & $\begin{array}{l}{ }^{\ddagger} \text { MRI: global severe atrophy, moderate } \\
\text { leukoaraiosis }\end{array}$ & $\begin{array}{l}\text { Bilateral temporo-parietal hypoperfusion, more } \\
\text { evident on the left }\end{array}$ \\
\hline
\end{tabular}

${ }^{*}$ SPPCD, syndrome of progressive posterior cortical dysfunction; ${ }^{\dagger} \mathrm{CCT}$, cranial computed tomography, ${ }^{\ddagger} \mathrm{MRI}$, magnetic resonance imaging; ${ }^{\circledR}$ SPECT, single photon emission computed tomography. "AD-SPPCD, patients with Alzheimer's disease meeting criteria for SPPCD; ${ }^{9} \mathrm{CBD}-\mathrm{SPPCD}$, patients with corticobasal degeneration meeting criteria for SPPC; ${ }^{*}$ DLB-SPPCD, patient with dementia with Lewy body meeting criteria for SPPCD.

Only five patients underwent complete neuropsychological evaluation resulting from the severity of the disease at first consultation.

All patients selected underwent conventional neurological and brief cognitive evaluations, neuroimaging and routine laboratory investigation. Structural imaging findings are reported in Table 2. Eleven patients had been submitted to magnetic resonance imaging (MRI) and one to computed cranial tomography (CCT). All patients presented varying degrees of diffuse cortical atrophy, ranging from mild to severe. Three patients also showed areas of focal atrophy (one occipital, one parietal and one frontotemporal).

Ten patients had been submitted to conventional single photon emission computed tomography (SPECT) (Table 2). Bilateral temporo-parietal hypoperfusion, more marked on one side, was observed in five patients. More focal or asymmetric findings were present in the other five patients.

Clinical diagnoses were possible or probable $\mathrm{AD}$ in seven patients, CBD in four, and DLB body in one.

\section{Discussion}

We described a group of twelve patients who all presented predominant progressive higher order visual symptoms.
When hearing the patient's or caregiver's complaints, the clinician should suspect dysfunction of the central visual processing pathways and check for visual acuity and presence of simultanagnosia, optic apraxia, ocular ataxia, visual agnosia and other features of SPPCD, so called "conventional parietal symptoms", such as limb apraxia and hemineglect.

The presenile onset in all our cases is congruent with the majority of studies to date on SPPCD. ${ }^{1,3,4,24}$ In our case series, there was only one patient with visuoperceptive symptoms. The lower frequency of cases presenting with visuoperceptive symptoms is similar to literature reports. ${ }^{1,3,4,24}$ Patients' visual difficulties and advanced stages of disease may have accounted for the very low MMSE scores in our sample. Impairment in visual processing might also have contributed to the low recall scores of simple line drawings from the Brief Cognitive Screening Battery. Although loss of memory was not the main complaint, most of the patients presented objective memory impairment in the tests.

Besides the uniformity of the SPPCD, patients frequently presented with additional symptoms and signs at onset or during the course of this syndrome which may be suggestive of several other degenerative diseases.

It is important to comment on the relationship between 


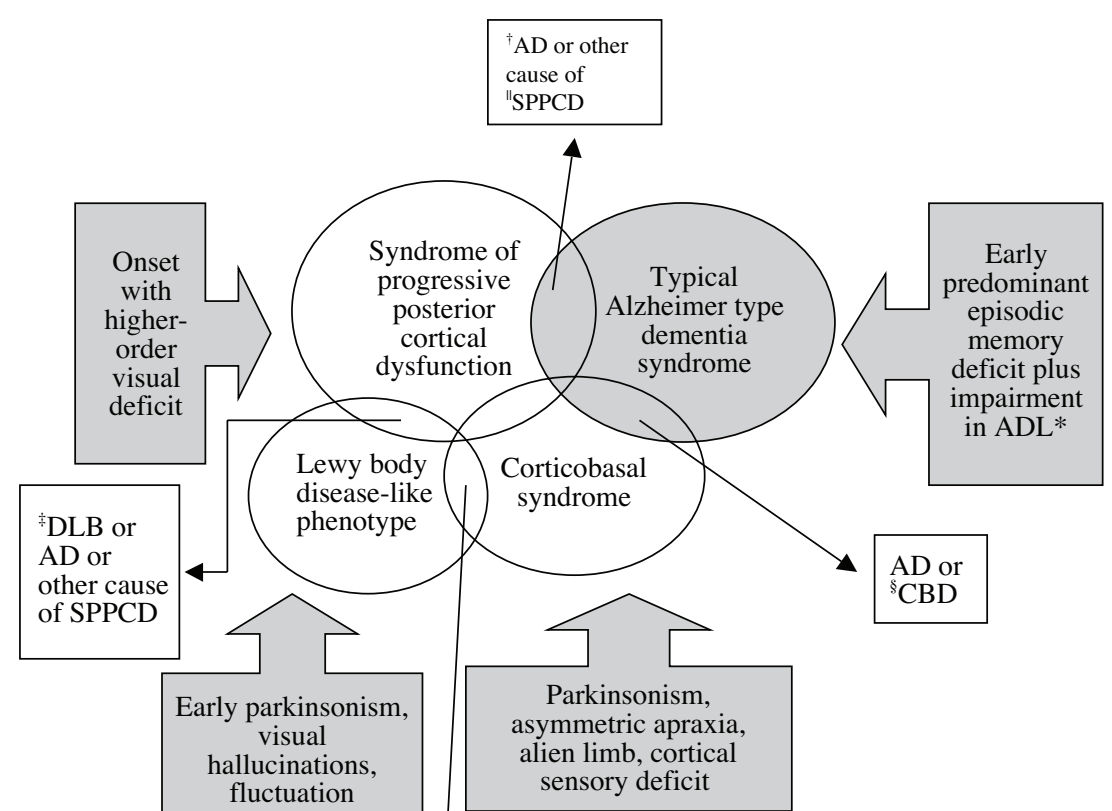

Figure 2. Diagram of overlapping clinical syndromes. ${ }^{\star} A D L$, activities of daily living; ${ }^{\dagger} A D$, Alzheimer's disease; ${ }^{*} D L B$, dementia with Lewy body; ${ }^{\S} \mathrm{CBD}$, corticobasal degeneration; "SPPCD, syndrome of posterior progressive cortical dysfunction.

the diagnosis of CBD and SPPCD. The classic description and diagnostic criteria of $\mathrm{CBD}^{12}$ apparently differ significant from SPPCD criteria. However, in everyday practice at a tertiary cognitive out-patient clinic, we occasionally encounter patients with overlapping symptoms of both conditions.

The symptom most strongly linked to CBD is apraxia. The limb apraxia is virtually always asymmetric and is most often ideomotor: patients are typically impaired in using tools, mimicking tool use and imitating mimes of tool use, while recognition of actions is usually relatively preserved. ${ }^{25}$ Visuospatial skills, when assessed, are found to be impaired: poor performance on the Benton's Judgment of Line Orientation Test ${ }^{26,27}$ and severe deficits in mechanical problem solving, which authors regarded as a predominantly high-level visuospatial ability linked to dorsal stream functions. ${ }^{28,29}$ Because the locus of pathology in CBD involves dorsal occipito-parietal, rather than more ventral occipito-temporal visual pathways, consequently such tasks should reveal selective breakdown in spatial processing. Recently, Mendez ${ }^{30}$ reported a patient with CBD and severe visuospatial impairment, in addition to all the features of Bálint's syndrome.

In our sample of patients, there are six patients with overlapping symptoms of CBD syndrome and SPPCD. Five of these patients had CBD as their final clinical diagnosis. Asymmetric parkinsonism was present in all of these patients, alien hand phenomena in 3 , hemineglect in 3 , prom- inent asymmetric apraxia syndrome in 6 and myoclonus in 2 . These patients presented predominantly high-order visual symptoms and clinical criteria of CBD at first or second consultation. Early parkinsonism, especially asymmetric, complaints that suggested very prominent apraxia syndrome, alien hand phenomena and cortical sensory deficits, called our attention. In fact, it is recommended that the cognitive evaluation of patients with suspected CBD should include not only a global dementia measure, such as the MMSE, but also at least a brief assessment of frontal/executive, visuospatial and language function. ${ }^{26}$

Also worthy of comment is the relationship of SPPCD with visual hallucinations and DLB. Visual hallucinations have been reported to occur in up to $25 \%$ of patients who met criteria for PCA. ${ }^{3,31}$ Josephs et al. ${ }^{32}$ studied clinical and imaging features of 59 patients with SPPCD and divided them into two groups: with $(\mathrm{N}=13)$ and without hallucinations $(\mathrm{N}=46)$. Hallucinations were associated with parkinsonism, rapid eye movement sleep behavior disorder and myoclonic jerks. Voxel-based morphometry results suggested hallucinations might involve a circuit of thalamocortical connections. The visual hallucinations were well formed, recurrent and spontaneous. All the patients with visual hallucinations met the clinical research criteria for probable DLB, ${ }^{13}$ although not at the base line evaluation.

Our series of cases included one patient who met clinical criteria for probable DLB around 2 years after 
SPPCD onset. The visual hallucinations were persistent, well formed and spontaneous and the neuropsychological profile consistent with DLB. These findings suggest that a patient who presents with the SPPCD may later progress into a DLB-like phenotype.

The presence of other features besides typical SPPCD, lead us to consider the differential diagnosis found in clinicopathologic studies.

The findings above reinforce the multiple etiologies of SPPCD. This does not however necessarily imply AD. SPPCD has also been reported in some patients with Pick's disease $^{7}$ and Creutzfeldt-Jakob disease (Heidenhain's type)..$^{7,33,34}$ The typical presentation of these diseases has features which are very distinct from SPPCD but in some circumstances symptoms may also overlap.

A diagram of the overlapping syndromes is shown in Figure 2.

In a recent study, forty patients with SPPCD were examined, nine of whom died and underwent autopsy. Brains of seven patients had $\mathrm{AD}$ pathology with neurofibrillary tangles (NFT) distributed predominantly in Brodmann's areas 17 and 18. Two cases showed corticobasal degeneration pathology. Complete and partial Bálint syndrome was found in 35 patients. Five patients had developed visual hallucinations and six parkinsonism during their illnesses. Two of these patients had AD and DLB at autopsy. ${ }^{3}$

Studies on neuropathology and anatomoclinical correlation concerning major damaged pathways in patients with AD, Bálint syndrome and SPPCD have found a global caudal shift in pathology, suggesting that the connections underlying this functional component of the visual system were "devastated", whereas they are normally less impaired in typical AD. ${ }^{35-41}$ Indeed, these papers suggest that there is not simply a caudal displacement in pathology, but also a selective loss of visual function. These patients were not blind nor did they have problems in form, shape or color recognition. The visual defects specifically affect the analysis of space and the detection of motion.

With regard to the clinical aspect, in 1909, Reszö Bálint originally described a complex visual syndrome which was first documented in an $\mathrm{AD}$ patient by Grünthal (cited by Hof et al.). ${ }^{35}$ More recently, Mendez and Cherrier ${ }^{42}$ have suggested an evolution of SPPCD progressing from a difficulty in visual integration beginning with letters, followed by impairment in interpretation of whole scenes, and finally culminating in Bálint's syndrome.

In contrast to the numerous studies on Bálint syndrome and visuospatial disturbance, less attention has been dedicated to visual agnosia. This may be because the condition is not usually reported, unlike visuospatial deficits. However, there have been a few case reports and se- ries of patients studied clinically and/or pathologically that presented visual object agnosia. . $^{31,35,36,38,41,43-45}$ The detailed pathological analysis of autopsies found a more extensive disconnection of a specific component of corticocortical visual associative systems. The distribution of lesions correlated well with neurological symptomatology presented and supports the hypotheses that long corticocortical projections are disrupted in $\mathrm{AD} .{ }^{46}$ Another study ${ }^{41}$ found a correlation between the NFT densities in Brodmann's areas 18, 19 and 37 and associative visual agnosia, whereas NFT in the areas studied did not correlate with apperceptive visual agnosia. These authors suggest that such results support the existence of a dichotomy between associative and apperceptive agnosia, showing that only the former is related to damage of secondary and high-order visual association areas in $\mathrm{AD}$.

We had a patient in our case series whose first manifestation was associative visual agnosia. She was unable to recognize objects but could name accurately them when allowed to touch them.

The findings of structural imaging have always drawn researcher's attention. In fact, early studies considered the finding of asymmetric posterior atrophy as important as the clinical picture per se. As more research groups began to recognize and follow these patients more closely, it became clear that focal posterior asymmetric atrophy is not mandatory for the diagnosis and may appear in late stages of the disease.

In our case series, three patients showed more focal atrophy while all presented diffuse atrophy ranging from mild to severe. All patients with AD showed cortical atrophy, and one patient with CBD presented left focal parietal atrophy. The retrospective nature of the study coupled with the fact that the patients were submitted to CCT or MRI in different stages of the disease might have accounted for these heterogeneous findings.

Previous articles on functional imaging include several single case reports and a few series of small samples. ${ }^{32,42,43,45,47-50}$ The most common finding of functional imaging in SPPCD is hypoperfusion or hypometabolism (with SPECT or positron emission tomography, respectively) in occipital and posterior parietal areas, usually more marked on the right side. Occasionally the temporal associative cortex is involved and frontal extension found. ${ }^{45,50}$ The frontal eye field hypometabolism may result from secondary loss of input from the occipito-parietal region. In our study, ten patients were submitted to conventional SPECT. Unilateral asymmetric findings were present in 3 patients. One of the patients clinically diagnosed with CBD presented left temporo-parietal hypoperfusion. The patient whose associate visual symptom was agnosia, 
showed marked bilateral temporal hypoperfusion. SPECT findings were also very heterogeneous. Unfortunately, the majority of the patients were submitted to SPECT only at late stages of the disease.

There are several major limitations in our study. It is a retrospective study based on chart information. Patients had been evaluated by several neurologists over the years, who had not been specifically searching for symptoms and signs resulting from posterior cortical impairment. Secondly, there was no neuropathological confirmation of the diagnosis in any of the patients. The absence of neuropathology studies leaves us with a presumptive diagnosis. Also, the patients did not undergo an ophthalmologic consultation, which would have been valuable to accurately measure their visual acuity and thus ensure the visual deficits were entirely or predominantly secondary to central associative visual pathways dysfunction. Another limitation is the profile of patients analyzed, since the group of patients was very heterogeneous with individuals having been examined at various stages of disease. The complete neuropsychological evaluation could not be done in all the patients, especially since some were already at moderate stages of the disease while social problems prevented them from returning regularly to our outpatient clinic.

However, this manuscript demonstrates the difficulties in classifying patients into groups of predetermined criteria, not to mention the frequency with which we encounter patients with overlapping features. Therefore, it is more prudent and didactic to classify patients into syndromes that may overlap at some point during the course of the disease. As the disease progresses, it becomes easier to classify the patients under specific clinical diagnostic criteria.

This paper aimed to raise physicians and researchers' awareness concerning this rare but important clinical entity. This awareness leads us to a better understanding of SPPCD and its association with other neurodegenerative diseases. Clinicians should consider this diagnosis in relatively young patients who have slowly progressive non-ocular visual complaints.

\section{References}

1. Benson F, Davis J, Snyder BD. Posterior cortical atrophy. Arch Neurol 1988;45:789-793.

2. Damasio AR. Disorders of complex visual processing: agnosias, achromatopsias, Balint's syndrome and related difficulties of orientation and construction. In: Mesulam MM, editor. Principles of behavioral neurology, Philadelphia: F.A. Davis Company; 1985:259-288.

3. Tang-Wai DF, Graff-Radford NR, Boeve BF, et al. Clinical, genetic and neuropathological characteristics of posterior cortical atrophy. Neurology 2004;63:1168-1174.
4. Mendez MF, Ghajarania M, Perryman KM. Posterior cortical atrophy: clinical characteristics and differences compared to Alzheimer's disease. Dement Geriatr Cogn Disord 2002;14:33-40.

5. Purvin V, Bonnin J, Goodman J. Palinopsia as a presenting manifestation of Creutzfeldt-Jacob disease. Am J Neuro-Ophtalmol 1989;9:242-246.

6. Vargas ME, Kupersmith MJ, Savino, et al. Homonymous field defect as first manifestation of Creutzfeldt-Jacob disease. Am J Neuro-Ophtalmol 1995;119:497-504.

7. Victoroff J, Ross W, Benson F, Verity A, Vinters HV. Posterior cortical atrophy. Neuropathologic considerations. Arch Neurol 1994;51:269-274.

8. Wenning GK, Litvan I, Jankovic J, et al. Natural history and survival of 14 patients with autopsy-confirmed corticobasal degeneration. J Neurol Neurosurg Psychiatry 1998;64:184-189.

9. Tang-Wai DF, Josephs KA, Boeve BF, Dickson DW, Parisi JE, Petersen RC. Pathologically confirmed corticobasal degeneration presenting with visuospatial dysfunction. Neurology 2003;61:1134-1135.

10. Renner JA, Burns JM, Hou CE, McKeel DW, Storandt M, Morris JC. Progressive posterior cortical dysfunction. A clinicopathologic series. Neurology 2004;63:1175-1180.

11. McKhann G, Drachman D, Folstein M, et al. Clinical diagnosis of Alzheimer's disease: Report of the NINCDS-ADRDA work group under the auspices of department of health and human services task force on Alzheimer's disease. Neurology 1984;34:939-44.

12. Litvan I, Bhatia KP, Burn DJ, et al. Movement Disorders Society Scientific Issues Committee. Movement Disorders Society Scientific Issues Committee report: SIC Task Force appraisal of clinical diagnostic criteria for Parkinsonian disorders. Mov Disord 2003;18:467-486.

13. McKeith IG. Consensus guidelines for the clinical and pathologic diagnosis of dementia with Lewy bodies (DLB): report of the Consortium on DLB International Workshop. J Alzheimers Dis 2006;9(3 Suppl):417-423

14. Folstein MF, Folstein SE, McHugh PR. Mini-Mental State: a practical method for grading the cognitive state for the clinician. J Psychiatr Res 1975;12:189-198.

15. Brucki SMD, Nitrini R, Caramelli P, Bertolucci PHF, Okamoto IH. Sugestões para o uso do mini-exame do estado mental no Brasil. Arq Neuropsiquiatr 2003; 61:777-781.

16. Nitrini R, Lefevre BH, Mathias SC, et al. Neuropsychological tests of simple application for diagnosing dementia. Arq Neuropsiquiatr 1994;52:457-465.

17. Nitrini R, Caramelli P, Herrera Junior E, et al. Performance of illiterate and literate nondemented elderly subjects in two tests of long-term memory. J Int Neuropsychol Soc 2004;10:634-638.

18. Takada LT, Caramelli P, Fichman HC, et al. Comparison between two tests of delayed recall for the diagnosis of dementia. Arq Neuropsiquiatr 2006;64:35-40. 
19. Miller E. Verbal fluency as a function of a measure of verbal intelligence and in relation to different types of cerebral pathology. Br J Clin Psychol 1984;8:385-394.

20. Brucki SMD, Rocha MSG. Category fluency test: effects of age, gender ad education on total scores, clustering and switching in Brazilian Portuguese-speaking subjects. Braz J Med Biol Res 2004; 37:1771-1777.

21. Lesak MD. Neuropsychological assessment. $3^{\text {rd }}$ ed. Nova York: Oxford University Press; 1995.

22. Weintraub S. Neuropsychological assessment of mental state. In: Mesulam MM, editor. Principles of behavioral neurology, Philadelphia: F.A. Davis Company;1985:121-173.

23. Baddley A. Working memory. Science 1992;255:556-559.

24. Croisile B, Trillet M, Hibert O, et al. Désordres visuo-constructifs et alexie-agraphie associés à une atrophie corticale postérieure. Rev Neurol (Paris) 1991;147:138-143.

25. Leiguarda R, Merello M, Balej J. Apraxia in corticobasal degeneration. In: Litvan I, Goetz CG, Lang AE, editors. Corticobasal degeneration. Philadelphia: Lippincott Williams \& Wilkins; 2000:103-121.

26. Graham NL, Bak TH, Patterson K, Hodges JR. Language function and dysfunction in corticobasal degeneration. Neurology 2003;61:493-499.

27. Graham NL, Zeman A Young AW, Patterson K, Hodges JR. Dyspraxia in a patient with corticobasal degeneration: the role of visual and tactile inputs of action. J Neurol Neurosurg Psychiatry 1999;67:334-344.

28. Hodges JR, Spatt J, Patterson K. "What" and "how": evidence for the dissociation of object knowledge and mechanical problem solving skills in the human brain. Proc Natl Acad Sci USA 1999;96:9444-9448.

29. Spatt J, Bak T, Bozeat S, Patterson K, Hodges JR. Apraxia, mechanical problem-solving and semantic knowledge: contribution to object usage in corticobasal degeneration. J Neurol 2002;249:601-608.

30. Mendez MF. Corticobasal ganglionic degeneration with Bálint's syndrome. J Neuropsychiatry Clin Neurosci 2000;12: 273-275.

31. McMonagle P, Deering F, Berliner Y, Kertesz A. The cognitive profile of posterior cortical atrophy. Neurology 2006;66:331-338.

32. Josephs KA, Whitwell JL, Boeve BF, et al. Visual hallucinations in posterior cortical atrophy. Arch Neurol 2006;63:1427-1432.

33. Nodera H, Mori A, Izumi Y, Sakamoto T, Kaji R. CreutzfeldtJakob disease manifesting as posterior cortical dementia. Neurology 2005;65:330.

34. Snowden JS, Mann DM, Neary D. Distinct neuropsychological characteristics in Creutzfeldt-Jakob disease. J Neurol Neurosurg Psychiatry 2002;73:686-694.

35. Hof PR, Bouras C, Constantinidis J, Morrison JH. Balint's syndrome in Alzheimer's disease: specific disruption of the occipito-parietal visual pathway. Brain Res 1989;493:368-375.

36. Hof PR, Bouras C, Constantinidis J, Morrison JH. Selective disconnection of specific visual association pathways in cases of Alzheimer's disease presenting with Bálint's syndrome. J Neuropathol Exp Neurol 1990;49:168-184.

37. Morrison JH, Hof PR, Bouras C. An anatomic substrate for visual disconnection in Alzheimer's disease. Ann N Y Acad Sci 1991;640:36-43.

38. Hof PR, Bouras C. Object recognition deficit in Alzheimer's disease: possible disconnection of the occipito-temporal component of the visual system. Neurosci Lett 1991;122:53-56.

39. Hof PR, Archin N, Osmand AP, et al. Posterior cortical atrophy in Alzheimer's disease: analysis of a new case and reevaluation of a historical report. Acta Neuropathol (Berl) 1993;86:215-23.

40. Hof PR, Vogt BA, Bouras C, Morrison JH. Atypical form of Alzheimer's disease with prominent posterior cortical atrophy: a review of lesion distribution and circuit disconnection in cortical visual pathways. Vision Res 1997;37:3609-3625.

41. Giannakopoulos P, Gold G, Duc M, Michel JP, Hof PR, Bouras C. Neuroanatomic correlates of visual agnosia in Alzheimer's disease: a clinicopathologic study. Neurology 1999;52:71-77.

42. Mendez MF, Cherrier MM. The evolution of alexia and simultagnosia in posterior cortical atrophy. Neuropsychiatry Neuropsychol Behav Neurol 1998;11:76-82.

43. Attig E, Jacquy J, Uytdenhoef P, Roland H. Progressive focal degenerative disease of the posterior associative cortex. Can J Neurol Sci 1993;20:154-157.

44. Levine DN, Lee JM, Fisher CM. The visual variant of Alzheimer's disease: a clinicopathologic case study. Neurology 1993;43:305-313.

45. Schmitdke K, Hüll M, Talazko J. Posterior cortical atrophy: a variant of Alzheimer's disease? A case series with PET findings. J Neurol 2005;27:27-35.

46. Flament S, Delacourte A, Delaère P, Duyckaertz C, Haw JJ. Correlation between microscopical changes and tau 64 an 69 biochemical detection in senile dementia of the Alzheimer's type. Tau 64 and 69 are reliable markers of the neurofibrillary degeneration. Acta Neuropathol 1990;80:212:215.

47. Freedman L, Selchen DH, Black SE, Kaplan R, Garnett ES, Nahmias CN. Posterior cortical dementia with alexia: neurobehavioral, MRI, and PET findings. J Neurol Neurosurg Psychiatry 1991;54:443-448.

48. Wakai M, Honda H, Takaha A, Kato T, Ito K, Hamanaka T. Unusual findings on PET study of a patient with posterior cortical atrophy. Acta Neurol Scand 1994;89:458-461.

49. Ross SJM, Graham N, Stuart-Green L, et al. Progressive biparietal atrophy: an atypical presentation of Alzheimer's disease. J Neurol Neurosurg Psychiatry 1996:61:388-395.

50. Nestor PJ, Caine D, Fryer TD, Clarke J, Hodges JR. The topography of metabolic deficits in posterior cortical atrophy (the visual variant of Alzheimer's disease) with FDG-PET. J Neurol Neurosurg Psychiatry 2003;74:1521-1529. 


\section{APPENDIX \\ Illustrative case report}

Case MNA - A 56-year-old right-handed ex-stewardess presented to the Behavioral and Cognitive Unit with a one-year history of progressive spatial disorientation. It first affected neighborhood disorientation and progressed to home disorientation. She kept repeating the same ideas. The caregiver also complained that the patient could not see what was in front of her and, when reaching for objects (such as door handle or sink tap), she missed them, and relied more on her touch than on eye sight. Family members noticed that she had begun having difficulty in performing home tasks some two years earlier. She needed help in instrumental activities of daily living, for instance, she was unable to use the phone, because she did not see the handset cradle and the numbers, she was unable to wash the dishes as she kept searching for the tap. She was confused with right and left hands. Throughout the course of the disease, the symptoms deteriorated and she had to be aided in basic activities of daily living, presented word-finding difficulties and worsened recent memory. She had discrete dyslipidemia and controlled hypothyroidism. She presented depressed mood. No family history of dementia was reported. On examination, she scored 9 out of 30 points on the MMSE. Mild asymmetric rigid-akinetic parkinsonism was present, being more prominent on the left side. She had difficulty in performing manual tasks under visual guidance bilaterally (optic ataxia), jerky intrusions when attempting to perform smooth pursuit eye movements (ocular apraxia) and could not see two objects at the same time (for instance, a pen and a watch) (simultanagnosia). When the examiner showed some dark line drawings pointing at one for her to name, she could only see the examiner's fingernail. She had difficulties in performing commands that required right and left orientation. There were normal optic fundi, brisk symmetric tendon reflexes and no frontal releasing signs. On subsequent examinations, the visual signs, recent memory and language functions, especially naming, reading and writing, deteriorated. She presented bilateral finger agnosia, total left spatial and somatosensory extinction, motor right hand extinction, intense bilateral ideomotor apraxia and acalculia. Insight and social adequacy were preserved until moderate stages of the disease. She presented a severe difficulty on confrontation field examination, because most of the time she could not see the target (simultanagnosia, ocular apraxia).

Neuropsychological evaluation evidenced intense visuospatial and visual analytic deficits. She could not perform the Hooper Visual Organization Test or the colored Progressive Raven Matrices. She was also unable to recognize the components of the Stanford-Binet Thematic Figure. The visual impairment precluded the evaluation of the other cognitive domains, especially language functions. She scored 69 out of 144 points in the Mattis dementia rating scale, with impairments in all domains, but particularly memory and constructional abilities. Severe difficulty was also seen in the Block Design Test, Trail Making A and Stroop tests. The MRI showed generalized atrophy with prominent bilateral parieto-occipital atrophy. The SPECT showed prominent hypoperfusion of parietal regions, especially on the right side and with right fronto-temporal extension. She was treated with cholinesterase inhibitors (rivastigmine and donepezil) and responded very poorly. 